\title{
A Comprehensive Review of Phytochemicals and Medicinal Use of Moringa oleifera
}

\section{Devlekar Shital $^{1 *}$, Khale Anubha ${ }^{2}$ and Rawal Jignyasha ${ }^{3}$}

${ }^{1}$ Pacific Academy of Higher Education and Research University, Udaipur, India

${ }^{2}$ Dean, Faculty of Sciences and Technology, SNDT Women's University, Mumbai, India

${ }^{3}$ Pacific Academy of Higher Education and Research University, Udaipur, India

*Corresponding Author: Devlekar Shital , PhD Scholar, Pacific Academy of Higher

Education and Research University, Udaipur, India
Received: May 27, 2021

Published: June 23, 2021

(C) All rights are reserved by Devlekar Shital., et al.

\begin{abstract}
Moringa oleifera is a plant Lam, also known as the horseradish tree, is a tropical tree that has been naturalised in Afghanistan, Florida, and East to West Africa. M. oleifera is well-known traditionally for its significant medicinal properties, in addition to its excellent nutritional value in different parts of the world. Many conventional folklore reports of the therapeutic uses of morphological sections of M. oleifera for different illnesses such as cardiac complaints, fevers, inflammation, stomach conditions, headaches, asthma, intestinal complaints, and rheumatism have been substantiated by scientific studies over the last few decades. Analgesic, anti-inflammatory, diuretic, antihypertensive, antioxidant, and anti-tumor properties are among the many pharmacological properties of M. oleifera. This Plant also contains a number of phytochemicals, some of which are of particular importance due to their medicinal potential. The M. oleifera is said to have beneficial properties in any aspect of the plant, contributing to its several and usefulness as a medicinal plant. This study would include an up-to-date compilation of published research data on M. oleifera in terms of medicinal properties, phytochemical composition, and recent developments in pharmacognosy. This plant's different sections contain a profile of essential minerals, well as protein, vitamins, carotene, amino acids, and various phenolics. Zeatin, quercetin, caffeoylquinic acid, and kaempferol are all found in abundance in the Moringa plant. Aside from its powerful water purifying properties, it also has a high nutritional value. The detailed phytochemical composition, medical applications, and pharmacological properties of various sections of this multipurpose tree are the subject of this study.
\end{abstract}

Keywords: Moringa oleifera; Medicinal Uses; Phytochemicals; Pharmacological Properties

\section{Introduction}

M. oleifera is widely regarded for its medicinal properties, in addition to its persuasive water purification and nutritional benefits. Various portions of this widely regarded tree have been attributed with medicinal properties. About any part of the tree, including the root, bark, gum, leaf, fruit (pods), flowers, seed, and seed oil, has been used in traditional medicine to treat a several of ailments. The $M$. oleifera vast therapeutic effects, as well as the wide range of pharmacological practises it exhibits, allow it a valuable tools for contributing to health and medicine as a panacea for a several of ailments. Moringa oleifera is the most widely distributed genus of the monogeneric Moringa oleiferaceae family, which comprises 13 species of trees and shrubs found in India, Sri Lanka, North Eastern and South Western Africa, and Madagascar's sub-Himalayan ranges. Sajina (Bengali); Horseradish tree, drumstick tree (English); Sahinjan (Hindi); Murinna (Malyalam); Sevaga (Marathi); Sobhanjana 
(Sanskrit); and Sehjan (Sanskrit) are some of the names given to it in various Indian languages and regions (Urdu). It grows wild and cultivated in the plains, preferring tropical habitats and being plentiful along river and stream sandy beds. The M. oleifera, a native of northern India's sub-Himalayan mountains, is now grown for a range of purposes in the world's tropical and subtropical regions. Similarly, the various vegetative and reproductive sections of the M. oleifera flower. Zaku., et al. (2015) recently published a study of the M. oleifera tree's prospects, focusing on its dietary and industrial applications, as well as its propagation methods. To achieve the desired population of 1666 trees/ha, it is propagated using cuttings (0.2-1.0 m long) with prescribed tree to tree spacing of 1.2 and $5 \mathrm{~m}$ between rows (for pod yield). Cuttings are cultivated with a near spacing for foliage development, resulting in a million trees per hectare. Because of the significant genetic variation caused by cross-pollination, seed propagation is not advised. The Moringa tree thrives in temperatures between 25 and $35^{\circ} \mathrm{C}$, in direct sunshine, at 500 metres altitude, and in mildly acidic to alkaline soil ( $\mathrm{pH} 5.0$ - 9.0); however, it can withstand temperatures as high as 48 degrees Celsius, frost in the winter, altitude, and a wide range of soil conditions. The $M$. oleifera seeds should be planted immediately after maturity because they do not go dormant and maintain viability for up to a year. The tree bears fruit between the ages of six and eight months, with a low fruit set in the first one or two years, but increasing yields in subsequent years. The Brazilian genotype's production was measured to be 45 tonnes of pods per hectare. After three years of planting, the Indian cultivar (PKM-1) yielded $258 \mathrm{~kg} / \mathrm{ha}$ of oil. It was cultivated in the subtropical northwestern region of Argentina. With an annual production of 1.1 - 1.3 million tonnes from a 38,000-hectare district, India is the world's largest producer of M. oleifera fruits (pods). Andhra Pradesh is India's largest producer, both in terms of area (15665 ha) and volume. Various portions of this widely regarded tree have been attributed with a several of medicinal properties. Almost all parts of this herb, including the base, bark, gum, leaf, berries, flowers, seed, and seed oil, have been used in South Asian traditional medicine to treat a several of illnesses, including inflammation and infectious diseases, as well as cardiovascular, gastrointestinal, haematological, and hepatorenal disorders. Moringa seeds are antipyretic, acrid, bitter, and have been stated to have antimicrobial properties. The seed can be eaten raw as peas, or pounded, fried, or pressed into sweet, non-desiccating oil known as high-quality 'Ben oil.' Its dried crushed seed and seed press cake, which contain polypeptides, have the special property of acting as natural coagulants for water treatment. So far, no systematic analysis of the literature has been compiled that covers the effectiveness of this plant in all dimensions. Its potential as a medication, nutritional food, nutraceutical, and water purifier prompted us to fill a knowledge gap in this field by writing a detailed analysis of the therapeutic, phytochemical, and pharmacological properties of this high-value herb. The Moringa oleifera has a lot of promise in terms of delivering inexpensive and easy-to-access medicinal value to communities in developing countries that are in desperate need of proper healthcare, particularly in areas where western medicine is unavailable. If medical research backs it up, dietary consumption of this plant should be promoted in these and other countries as a low-cost prevention method for a several of diseases. The current study will include an updated overview of $M$. oleifera common medical applications, phytochemical composition, and recent advancements in pharmacological research [1].

\begin{tabular}{|c|c|c|c|}
\hline $\begin{array}{l}\text { Plant } \\
\text { name }\end{array}$ & Medicinal use & $\begin{array}{c}\text { Traditional method for } \\
\text { preparation }\end{array}$ & Phytochemical constituent \\
\hline Plant & $\begin{array}{l}\text { Used as a laxative, astringent, diuretic, Cardiotonic, } \\
\text { abortifacient and rubefacient. } \\
\text { Treats toothaches, common colds, external sores, } \\
\text { inflammations, stomatitis, piles, bronchitis, urinary } \\
\text { discharges, Obstinate asthma, rheumatism, epilepsy. } \\
\text { Useful for lower back and kidney pain and constipa- } \\
\text { tion and as a stimulant for nervous debility, paralytic } \\
\text { afflictions, Hysteria and epilepsy. }\end{array}$ & Prepared as decoctions & $\begin{array}{l}\text { Benzylglucosinolate Aurantiamide } \\
\text { acetate } 1,3 \text { dibenzyl urea }\end{array}$ \\
\hline Bark & $\begin{array}{l}\text { Useful for heart complaints, eye diseases, fevers, } \\
\text { inflammation, dyspepsia and Enlargement of spleen. } \\
\text { Relieves earaches, Toothaches. Treats sores, colds, } \\
\text { digestive Disorders, hysteria, headaches. Used as an } \\
\text { Aphrodisiac. }\end{array}$ & $\begin{array}{l}\text { Decoctions for creams or } \\
\text { Emollients }\end{array}$ & $\begin{array}{l}\text { Alkaloids (moringine; moringi- } \\
\text { nine) } \\
\text { Vanillin } \beta \text {-sitosterol Otacosanoic } \\
\text { acid }\end{array}$ \\
\hline
\end{tabular}




\begin{tabular}{|c|c|c|c|}
\hline Gum & $\begin{array}{l}\text { Used as an astringent, rubefacient and Abortifacient. } \\
\text { Used to relieve toothaches, headaches, fevers, intesti- } \\
\text { nal complaints, Dysentery and asthma. Treats syphilis } \\
\text { and Rheumatism. }\end{array}$ & $\begin{array}{l}\text { Used to season food prepa- } \\
\text { rations }\end{array}$ & $\begin{array}{l}\text { Arabinose Galactose Glucoronic } \\
\text { acid } \\
\text { Rhamnose Mannose } \\
\text { Leucoanthocyanin }\end{array}$ \\
\hline Leaf & $\begin{array}{l}\text { Used as an anti-helminthic and Aphrodisiac. Treats } \\
\text { hypocholesteremia, Diarrhea, colitis and rheumatism. } \\
\text { Reduces Glandular swelling and headaches. Used for } \\
\text { piles, fevers, constipation, bronchitis, Ear and eye } \\
\text { infections, scurvy and catarrh. } \\
\text { Promotes digestion and used as a poultice } \\
\text { For sores. }\end{array}$ & $\begin{array}{l}\text { The leaves are cooked and } \\
\text { used } \\
\text { Like spinach. Leaves are also } \\
\text { commonly dried and } \\
\text { crushed into } \\
\text { a powder, and used in soups } \\
\text { and } \\
\text { Sauces. }\end{array}$ & $\begin{array}{c}\text { Catechol tannins Steroids } \\
\text { Triterpenoids Flavonoids Sapo- } \\
\text { nins } \\
\text { Anthraquinones Alkaloids } \\
\text { Glucosinolate Carotenoids Ascor- } \\
\text { bic } \\
\text { acid Vitamins Isothiocyanates } \\
\text { Tannins }\end{array}$ \\
\hline Flower & $\begin{array}{c}\text { Treats inflammations, bacterial infections, common } \\
\text { colds, external sores/ulcers, throat infections, muscle } \\
\text { diseases, tumors } \\
\text { And cholera. Used as a diuretic, Aphrodisiac and } \\
\text { abortifacient. Folk remedies or tumors }\end{array}$ & $\begin{array}{l}\text { Flower extracts are used } \\
\text { for preparations to enhance } \\
\text { taste and Color in dishes. }\end{array}$ & $\begin{array}{c}\text { Galactose Glucoronic acid Ascor- } \\
\text { bic acid Tocopherols Kaempherol, } \\
\text { Rhamnetin, Isoquercitrin Kaemp- } \\
\text { feritrin }\end{array}$ \\
\hline Pod & $\begin{array}{l}\text { Used as a tonic and against helminthes And skin } \\
\text { tumors. Treats diabetes and joint Pains. }\end{array}$ & $\begin{array}{l}\text { Young pods are sliced and } \\
\text { boiled In water with salt. } \\
\text { Mature pods are twisted } \\
\text { open, are removed and fried } \\
\text { in oil or cooked like pea, } \\
\text { fresh or dried }\end{array}$ & $\begin{array}{l}\text { Nitriles Isothiocyanates } \\
\quad \beta \text {-sitosterol } \\
\text { Galactose D-galacturonic acid } \\
\text { L-arabinose L-rhamnose }\end{array}$ \\
\hline Seed & $\begin{array}{l}\text { Cures eye diseases and head complaints. } \\
\text { Used for treatment of fevers, snake bites, } \\
\text { Scorpion stings and warts. Treats ulcers, gastritis, } \\
\text { skin disorders, bladder infections, scurvy, abdominal } \\
\text { tumors and Schistosomes. Removes harmful bacteria. }\end{array}$ & $\begin{array}{l}\text { Seeds are prepared green, } \\
\text { roasted or powdered, } \\
\text { steamed and extracted as } \\
\quad \text { an oil }\end{array}$ & $\begin{array}{l}\text { Benzylglucosinate } \\
\text { Di-oleic-triglyceride } \\
\text { Mono-palmitic acid }\end{array}$ \\
\hline $\begin{array}{c}\text { Seed } \\
\text { oil }\end{array}$ & $\begin{array}{l}\text { Used as a purgative. Useful in leprosy and } \\
\text { Ulcers. Treats rheumatism, gout, skin Pathogens, } \\
\text { lupus and bladder disorders. } \\
\text { Improves prostate function. }\end{array}$ & $\begin{array}{l}\text { Used in water treatment and } \\
\text { Purification }\end{array}$ & $\begin{array}{c}\text { Tocopherols Palmitic acid Stearic } \\
\text { acid } \\
\text { Arachidic acid } \\
\text { Phenylacetonitrile }\end{array}$ \\
\hline
\end{tabular}

Table 1: Common medicinal uses and phytochemical composition of $M$. oleifera tree morphological parts.

\section{Phytochemical composition}

Special glucosinolates, flavonoids and phenolic acids, carotenoids, tocopherols polyunsaturated fatty acids, highly bioavailable minerals, and folate have all been discovered in various parts of the Moringa oleifera tree. 4-0-(a-L-rhamnopyranosyloxy)-benzylglucosinolate is the most abundant glucosinolate in $M$. oleifera stem, leaves, flowers, pods, and seeds. ${ }^{1}$ While benzyl glucosinolate is the most prevalent in the roots. The leaves and seeds have the highest glucosinolate value. Endogenous plant enzyme myrosinase catabolizes glucosinolates to manufacture isothiocyanates, nitriles, and thiocarbamates, which have potent hypotensive and spasmolytic properties. Except for the roots and seeds, flavonol glycosides of quercetin [kaempferol isorhamnetin] are primarily present in different parts of the tree. The amounts of quercetin and kaempferol in the leaves were found to be in the range of 0.07 1.26 percent and $0.05-0.67$ percent, respectively [2]. In addition, as compared to African indigenous studies, Indian varieties have a higher overall content of quercetin and kaempferol. The high concentration of these polyphenols is responsible for Moringa oleifera potent antioxidant function. Recently, the polyphenolic, nutrient, and antioxidant capacity of seven main Moringa oleifera cultivars from Pakistan has been studied. The main flavonoids contained in the hydromethanolic extracts of Moringa foliage were quercetin, apigenin, and kaempferol derivatives, which accounted for 47.0, 
20.9 , and 30.0 percent of the total flavonoids, respectively. When phenolic concentrations and antioxidant potential of the measured foliage were compared to other big Moringa oleifera cultivars, 'Techiman' emerged as the most nutritive cultivar. The main types of folates present in Moringa oleifera vegetation are 5-Formyl5,6,7,8-tetrahydrofolic acid (5-HCO-H4folate; $502.1 \mathrm{lg} / 100 \mathrm{~g} \mathrm{DW}$ ), 5,6,7,8-tetrahydrofolic acid (H4folate; $223.9 \mathrm{lg} / 100 \mathrm{~g} \mathrm{DW}$ ), 5-Methyl-5,6,7,8-tetrahydrofolic acid [3]. Furthermore, as opposed to other folate-rich foods like green leafy vegetables, these types are particularly bioavailable in animals. The response of Moringa folates in a rat model was compared to the response of synthetic folic acid, yielding a relative bioavailability of 81.9 percent. Just $50 \%$ of natural folate is thought to be bioavailable in the RDA calculations [4]. Because of the slightly higher bioavailability of Moringa oleifera based food in animals, it is proposed that it may be used as a major source of folate. Folate, one of the most important water-soluble vitamins, is required for a several of cellular metabolisms, including one-carbon unit oxidation and reduction. Kasolo., et al. (2010) found catechol tannins, Gallic tannins, steroids, triterpenoids, flavonoids, saponins, anthraquinones, alkaloids, and reducing sugars in ether, ethanol, and water extracts of the leaves, all of which add to its pharmacological benefit. Hexadecanoic acid, ethyl palmitate, palmitic acid ethyl ester, 2, 6-dimethyl-1, 7-octadiene-3-ol, 2-hexanone, and 3-cyclohexyliden-4-ethyl-E2-dodecenylacetate were among the phytochemicals found by Nepolean., et al. (2009) in the leaves. M. oleifera gum contains aldotriouronic acid, which is characterized as O-(-D-glucopyranosyluronic acid) (16) and is derived by the acid hydrolysis of gum. (1 6) -D-galactopyranosyl D-galactose is a sugar that is produced in the body. Just 4-(alphalrhamnopyranosyloxy) - benzylglucosinolate was present in the bark tissue of $M$. oleifera. Both 4-(alpha-l-rhamnopyranosyloxy)benzylglucosinolate and benzyl glucosinolate are abundant in the roots of $M$. oleifera [4]. Compounds aurantiamide acetate 4 and 1 , 3-dibenzyl urea 5 were isolated and characterized from the roots of $M$. oleifera for the first time, which was a first for this genus. In ether, ethanol, and aqueous extracts of the roots, protective phytochemicals such as Gallic tannins, catechol tennins, steroids and triterponoids, saponins, anthraquinones, alkaloids, and reducing sugars were discovered [5]. In Moringa oleifera tissues, potassium $(\mathrm{K})$, calcium $(\mathrm{Ca})$, and magnesium $(\mathrm{Mg})$ are the most abundant minerals. The vegetative sections and immature pods contain the most $\mathrm{K}$, while the leaves and seeds contain the most $\mathrm{Ca}$ and $\mathrm{Mg}$, respectively. The $M$. oleifera is also noted for possessing high iron (Fe) content (17.5 mg/100 g DW) [6]. In the treatment of iron de- ficiency, Fe from Moringa leaf was found to be superior to ferric citrate. Significant improvements in the expression of liver hepcidin and other liver ironresponsive genes have also been observed in response to Fe deficiency, implying that relative expression of liver hepcidin mRNA may be used as the most sensitive molecular marker to diagnose iron deficiency in animals. Because of its slightly higher bioavailability, animal bioavailability studies indicate that Moringa foliage can be used as a major source of iron.

Protein content is high in both full-fat and defatted Moringa oleifera kernels, accounting for 36.18 and 62.76 percent, respectively [5]. In comparison to full-fat wheat, the amounts of the other proximate constituents were observed to be higher in defatted flour. Defatting flour also improved its water and fat absorption, foaming capability, and foam stability. The Moringa oleifera kernel flour, according to the reviewer, may be used as a valuable source of protein in food product formulation. The dehydrated leaf powder was found to contain 44.4 percent starch, $28.7 \%$ crude protein, 10.9 percent ash, 7.1 percent fat, $103.1 \mathrm{mg} / 100 \mathrm{~g}$ iron, and $3.0 \mathrm{mg} / 100$ g calcium in proximate studies from Brazil. Insoluble proteins accounted for 70.1 percent of the protein profile, with 3.5 percent glutelin, 3.1 percent albumin, 2.2 percent prolamin, and 0.3 percent globulins. ${ }^{6}$ Tannins (20.7 mg/g), trypsin inhibitor $(1.45 \mathrm{TIU} \mathrm{mg} / \mathrm{g}$; Trypsin Inhibitor Units), nitrates $(17 \mathrm{mg} / \mathrm{g})$, and oxalic acids (10.5 $\mathrm{mg} / \mathrm{g}$ ) were all found to be antinutritional.

\section{Pharmacological properties and medicinal applications}

The Moringa oleifera also has a several of medicinal properties that have long been recognized in the Ayurvedic and Unani medical systems. The medicinal properties and pharmacological activities of Moringa's different sections are described below.

\section{Anti-inflammatory properties}

Some chronic illnesses have inflammation as a symptom.

It is the body's own defence reaction to tissue damage caused by physical trauma, chemicals, or microbial agents. Anti-inflammatory agents are responsible for relieving discomfort and reducing inflammation, as well as improving overall wellbeing. Non-steroidal anti-inflammatory medications (NSAIDs) are widely used to treat inflammatory disorders, but they come with a slew of negative side effects, including gastric irritation, ulcers, and more. Because of their protection and usefulness, using medicinal plants as antiinflammatory agents is seen as a feasible and reasonable option. The 
M. oleifera tree is said to contain 36 anti-inflammatory compounds, all of which are found naturally. The anti-inflammatory efficacy of aqueous root extracts of $M$. oleifera $(750 \mathrm{mg} / \mathrm{kg})$ was found to be comparable to that of the powerful anti-inflammatory medication indomethacin [6]. At a dosage of $3 \mathrm{mg} / \mathrm{kg}$ body weight, crude ethanolic extracts of the seeds decreased inflammation against carrageenan-induced hind paw oedema in mice by 85 percent, while mature seeds reduced oedema by 77 percent. Infusions of leaves, berries, bulbs, roots, and bark in hot water also showed activity. Active compounds that are used to treat chronic and acute inflammatory disorders were shown to have anti-inflammatory properties. Alhakmani., et al. (2013) used the protein denaturation approach to examine the anti-inflammatory role of $M$. oleifera flowers. As a normal agent, diclofenac sodium, a potent non-steroidal anti-inflammatory drug, was used. The flower extracts (100-500 g/mL) inhibited heat-induced protein denaturation in fresh egg albumin in a dose-dependent proportion that was equivalent to the reference drug (100 and $200 \mathrm{~g} / \mathrm{mL}$ ) [7].

\section{Antioxidant properties}

Antioxidants are compounds that provide free atoms to the human body while also inhibiting free radicals that trigger cell destruction and oxidative stress. They've also been shown to help monitor the ageing process and reduce the incidence and development of many acute and chronic diseases including cancer, heart disease, and stroke. Natural antioxidants are abundant in medicinal plants. Drumstick leaves are said to be a good source of flavonoids, quercetin, and zeatin, which are all natural antioxidants [7]. The scavenging effects of mature and tender leaf extracts on free radicals, superoxide, and nitric oxide radicals have been documented. As compared to the well-known antioxidant ascorbic acid (IC50 $56.44 \mathrm{~g} / \mathrm{mL}$ ), methanolic extracts of the leaves display strong antioxidant activity (IC50 $49.86 \mathrm{~g} / \mathrm{mL}$ ). The dominant constituent of $M$. oleifera leaves that contributes to this behavior was discovered to be the primary bioactive compound of phenolics. The antioxidant function of methanolic extracts of the pods was equivalent to that of ascorbic acid against 2, 2-diphenyl-1-picrylhydrazyl (DPPH) free radicals and NO [7]. The antioxidant activity of seed oil was higher than that of butylated hydroxyl toluene (BHT) and alpha-tocopherol. The DPPH and 2,2'-azino-bis 3-ethylbenzothiazoline-6- sulphonic acid (ABTS) methods were used to establish the antioxidant activities of M. oleifera leaf extracts in different sol- vents (methanol, ethyl acetate, dichloromethane, and n-hexane). In the DPPH assay, the methanol extract had the highest free radical scavenging activity (IC50 $49.30 \mathrm{~g} / \mathrm{mL}$ ) and the ABTS assay had the lowest (IC50 $11.73 \mathrm{~g} / \mathrm{mL}$ ).

Activities that are antihypertensive, diuretic, and cholesterol lowering

This plant's pervasive mix of diuretic, lipid-lowering, and bloodpressure-lowering constituents makes it extremely beneficial for cardiovascular disorders. Blood pressure has been shown to be stabilized by Moringa leaf juice. The Moringa leaves included nitrile, mustard oil glycosides, and thiocarbamate glycosides, which were found to be responsible for the blood pressure lowering effect [8]. The majority of these molecules are fully acetylated glycosides, which are very unusual in nature and have thiocarbamate, carbamate, or nitrile groups. The isolation of four pure compounds, niazinin A [1], niazinin [1] B, niazimicin [4], and niazinin A + B, from the active ethanol extract of Moringa leaves was driven by bioassays. Niazinin A [1], niazinin [1] B, niazimicin [4], and niazinin A $+B$, showed a blood Another research using ethanol and aqueous extracts of whole pods and their components, such as coat, pulp, and seed, found that the blood pressure-lowering effect of the seed was more pronounced, with similar findings in both ethanol and water extracts, showing that the activity is widespread. The separation of thiocarbamate and isothiocyanate glycosides, which are understood to be hypotensive concepts, was achieved by activitydirected fractionation of an ethanol extract of $M$. oleifera pods. Methyl phydroxybenzoate found in M. oleifera pods; have also demonstrated encouraging hypotensive behavior. The diuretic function of Moringa roots, leaves, bulbs, gum, and the aqueous infusion of seeds has been discovered, and these diuretic components are likely to play a complementary role in the plant's overall blood pressure lowering effect. The presence of a bioactive phytoconstituent, namely, in the rudimentary extract of Moringa leaves has a major cholesterol lowering effect in the serum of high fat diet fed rats. In hypercholesteremic rabbits, Moringa fruit was observed to lower serum cholesterol, phospholipids, triglycerides, low density lipoprotein (LDL), very low density lipoprotein (VLDL) cholesterol to phospholipid ratio, atherogenic index lipid, and reduced the lipid profile of the liver, heart, and aorta, as well as increase fecal cholesterol excretion. 
Anti-tumor and anti-cancer properties

Medicinal plants have long been recognized as important suppliers of highly effective conventional drugs used to treat a several of cancers. Plants are also often used in the manufacture of clinically beneficial antitumor compounds that can be turned into anticancer drugs. One of the main benefits of using food or natural compounds as a cancer adjuvant is that they are poor in toxicity and have little negative side effects.

In HeLa cells, M. oleifera aqueous leaf extract demonstrated potent anticancer activity by stimulating the apoptotic pathway. With an ID50 of $0.32 \mathrm{~g} / \mathrm{mL}$, methanolic leaf extracts demonstrated cytotoxic activity against human multiple myeloma (U266B1) cells. Earlier experiments have demonstrated that ingesting drumstick extracts prevents skin tumors, with a dramatic decrease in skin papilloma in a mouse model that tested $M$. oleifera gum as a carrier for colon specific drug distribution. Drug release trials of rat caecal contents were also used to test $M$. oleifera gumto colonic bacteria resistance and drug release in the colon. Their findings revealed that a mixture containing $30 \%$ and $40 \%$ M. oleifera gum released a considerable amount of the medication curcumin (45.89 percent and 34.79 percent, respectively) into the colon's atmosphere [9]. $M$. oleifera leaves that may be used to cure myeloma patients with herbs. According to a recent review, phenolics and flavonoids found in fractions of M. oleifera extracts, specifically kaempferol can serve as potential cancer chemopreventive agents by reducing the proliferation of human carcinoma cancer cells by inducing in vitro apoptosis. Furthermore, quercetin and quercetin-50,8-disulfonate were shown to have potent antitumor activity against MCF-7 human breast cancer cells through a ROS-dependent apoptotic pathway, indicating that quercetin and its derivatives have great potential as anticarcinogenic agents and antitumor precursor compounds [9].

Hepatoprotective, antispasmodic, and antiulcer properties

Antispasmodic activity has been identified in M. oleifera roots. Moringa leaves have been widely researched pharmacologically, and the ethanol extract and its constituents have been discovered to have antispasmodic properties, likely by calcium channel blockade. The existence of 4-[-(L-rhamnosyloxy) benzyl]- o-methyl thiocarbamate (trans), which forms the basis for its common usage in diarrhea, has been due to the antispasmodic action of the ethanol extract of M. oleifera leaves. Furthermore, the spasmolytic function of various constituents provides a pharmacological foundation for the plant's conventional application of gastrointestinal motility disorders. Pal., et al. 1995 found that aqueous leaf extracts had an antiulcer effect, suggesting that the antiulcer portion is widely dispersed in this plant.

Moringa roots have also been shown to have hepatoprotective properties. The presence of quercetin, a well-known flavonoid with hepatoprotective activity, in the aqueous and alcohol extracts from Moringa flowers was also found to have a major hepatoprotective effect, which may be attributed to the presence of quercetin, a wellknown flavonoid with hepatoprotective activity [9].

\section{Antibacterial and antifungal properties}

Antimicrobial resistance has heightened interest in medicinal plants with antimicrobial properties and microbial compounds. This susceptibility may be due to indiscriminate utilization of commercial medications or unfavorable antibiotic side effects. Because of the high cost of conventional medications, more people are turning to plants as a therapeutic option for infectious diseases. Antimicrobial plant extracts and phytochemicals are extremely important in medicinal procedures. Antimicrobial activity has been found in sections of M. oleifera. The aqueous and ethanolic leaf extracts of M. oleifera had antibacterial activity against Salmonella spp., while the acetone leaf extracts had antibacterial activity against Escherichia coli, Enterobacter cloacae, Proteus vulgaris, Staphylococcus aureus, and Micrococcus kristinae at a concentration of $5 \mathrm{mg} / \mathrm{mL}$, with M. kristinae being the most Saponins, tannins, phenols, and alkaloid phytoconstituents were found to have antibacterial properties. P. aeruginosa (13.1 $0.1 \mathrm{~mm})$, S. aureus $(16.00 .2 \mathrm{~mm})$, and $E$. coli $(10.20 .2 \mathrm{~mm})$ were all inhibited by petroleum ether extracts of M. oleifera roots, according to Raj., et al. (2011). Ethanol extracts were active against $P$. aeruginosa $(12.10 \mathrm{~mm})$, S. aureus $(11.00 .2$ $\mathrm{mm})$, E. coli (9.2 $0.2 \mathrm{~mm}$ ), and Proteus mirabilis (8.1 $0.1 \mathrm{~mm})$, while chloroform and aqueous extracts were active against $P$. aeruginosa (12.20 $\mathrm{mm}$ and $11.20 .2 \mathrm{~mm}$ ) and E. coli $(10.1 \mathrm{~mm}$ and $8.20 .3 \mathrm{~mm}$ Aqueous extracts of $M$. oleifera seeds were shown to have effective inhibitory effects on $S$. aureus (19-25 mm), Vibrio cholera (21-25 $\mathrm{mm}$ ), and Escherichia coli (16-23 mm) by Vieira., et al. (2010).

\section{Antidiabetic properties}

Diabetes mellitus is the world's most prevalent metabolic disease and a major public health problem. It causes hyperglycemia, which can lead to microvascular and macrovascular complications 
and, in the worst-case scenario, death. Synthetic oral agents and insulin therapy are used to treat hyperglycemia, although these medications have harmful side effects and are prohibitively costly for the poor, especially in developing countries. As a result, the need for cost-effective and reliable hypoglycemic agents with fewer side effects will still exist. In various cultures, herbal preparations have been used for decades to cure diabetes. In streptozotocin-induced sub, moderate, and extreme diabetic rats, Jaiswal., et al. (2009) tested the antidiabetic efficacy of aqueous leaf extracts of $M$. oleifera (200 mg/kg). During fasting blood glucose and oral glucose tolerance test trials, a dosage of $200 \mathrm{mg} / \mathrm{kg}$ reduced blood glucose levels in normal animals by 26.7 percent and 29.9 percent, respectively [10]. During OGTT trials, extracts produced a maximum decrease of 31.1 percent and 32.8 percent in sub and mild diabetic animals, respectively. After 21 days of therapy, diabetic animals' FBG and postprandial glucose (PPG) levels were lowered by 69.2 percent and 51.2 percent, respectively, while total protein, body weight, and haemoglobin were raised by 11.3 percent, 10.5 percent, and 10.9 percent [11]. The anti-diabetic function M. oleifera humans has been studied in a few trials. Hypoglycemic impact of $M$. oleifera leaf dietary intake in chronic Type 2 diabetes patients aged 30-60 years over a 40-day cycle. The experimental group had 46 participants, 32 men and 14 women, while the control group had 9 participants, 4 men and 5 women. A daily dosage of $8 \mathrm{~g}$ M. oleifera leaf powder was given to the experimental sample. In terms of relative content of food sources, nutrients, and calories consumed, all groups' daily meals were similar. FPG and PPPG levels in the test group did not differ significantly from normal, but they were significantly lower in the experimental community.

\section{Cardiovascular exercise}

CVD refers to a group of illnesses and disorders that affect the heart and blood vessels, and it is the leading cause of death worldwide. For centuries, medicinal plants have been used to cure cardiovascular disease. This may be due to their antioxidant, vasodilator, adrenoceptor, and platelet activating factor (PAF) antagonist properties [12]. Many surgical therapies for any of these plants' cardiovascular functions have been investigated in patients with hypertension, hyperlipidemia, thromboembolism, coronary heart disease, congestive heart failure, angina pectoris, atherosclerosis, cerebral insufficiency, venous insufficiency, arrhythmia, among other conditions. Chumark., et al. (2008) investigated the therapeu- tic potential of $M$. oleifera leaves in the treatment of dyslipidemia in rabbits fed a high-cholesterol (5\%) diet for 12 weeks. The HCD-fed rabbits' plasma amounts of total cholesterol (TC), high density lipoprotein (HDL-C), low density lipoprotein (LDL-C), and triglycerides both increased after the procedure (TG). The diet has resulted in the development of a lot of plaque in the carotid arteries. The following elevations were reduced in HCD rabbits that were given M. oleifera aqueous extract at a daily dosage of $100 \mathrm{mg} / \mathrm{kg} \mathrm{b.w.} \mathrm{for}$ the length of the protocol: Randriamboavonjy., et al. (2016) investigated the cardiac effects of $M$. oleifera seed powder given orally to spontaneously hypertensive rats. SHR was given either powdered food ( $750 \mathrm{mg}$ /day for 8 weeks) or regular food. After that, hemodynamic parameters were measured in vivo. M. oleifera therapies did not change blood pressure in SHR but did lower nocturnal heart rate and increase cardiac diastolic activity, according to the findings. The thickness of the anterior wall of the left ventricle (LV), the inter-septal thickness on diastole, and the relative wall thickness all decreased after surgery. They also discovered that M. oleiferatreated SHR had significantly less fibrosis in the left ventricle.

\section{Central nervous system activity}

xhuman body. Many of the body's functions, such as coordination, breathing, memory, mental processing, and heart function, are affected by degenerative nerve disorders like Alzheimer's disease. These illnesses are incurable and sometimes fatal. The most often used pharmacological agents are those that function on the central nervous system. The processes by which different drugs function on the CNS is not always well understood. Many medicinal plants have been shown to have efficacy against CNS conditions and to be effective pain and discomfort relievers. It's becoming increasingly necessary to find drugs that treat these diseases with greater efficacy and fewer side effects. Since there is a scarcity of knowledge in the scientific literature on this topic, there is a growing need to investigate and revisit some of the well-controlled studies that have reported $M$. oleifera various CNS activities. Muscle spasms and spasticity are treated with skeletal muscle relaxants. Owing to their several side effects and contraindications, current antispasmodic medications such as cyclobenzaprine and antispasticity agents such as dantrolene are used with care in elderly patients. (Bhattachary 2014). The actophotometer test looked at the CNS, while the rotarod test looked at muscle relaxant behavior. The albino rats were split into six groups, each with six rats. 
The study groups were given extracts at doses of 50,100, 200, and $400 \mathrm{mg} / \mathrm{kg}$, respectively [13]. The control group was given natural saline solution orally $(2 \mathrm{ml} / \mathrm{kg})$, another group was given the standard drug Diazepam (10 mg/kg), and the third group was given the extracts at doses of 50,100,200, and $400 \mathrm{mg} / \mathrm{kg}$, respectively. In a dose-dependent manner, ethanolic extracts of $M$. oleifera demonstrated substantial CNS depressant and muscle relaxant action. Compounds found in plants, such as flavonoids and saponins, can quickly cross the blood-brain barrier and exert a several of effects on the CNS, including memory, perception, and neurodegeneration, or have an agonistic function on the GABA acid receptor complex, which may explain its CNS depressant and muscle relaxant properties.

Bakre., et al. (2013) investigated the neurobehavioral and anticonvulsant properties of an ethanol extract from M. oleifera leaves. The open area, whole board, Y-maze EPM, and pentobarbitone-induced hypnosis were used to assess neuro-behavioral properties. The anticonvulsive effects of $M$. oleifera were investigated using pentylenetetrazol and picrotoxin-induced convulsion experiments. Extract (250-2000 mg/kg) reduced rearing, shaving, head dips, and locomotion in a dose-dependent manner. It also improved learning and memory, as well as having an anxiogenic effect. Furthermore, the extract $(2000 \mathrm{mg} / \mathrm{kg})$ saved mice from pentylenetetrazol-induced convulsion, but not from picrotoxin- or strychnineinduced convulsion. In the different versions, the extract's effects were similar to those of the typical medications used. The authors concluded that the leaves had CNS depressant and anticonvulsant effects, which were likely regulated by an enhancement of the central inhibitory pathway involving GABA acid release [14].

\section{Conclusion}

Moringa oleifera is a remarkable tree because of its excellent nutritional and medicinal importance. It has tremendous promise in terms of offering a low-cost and reliable solution to not only healthy eating, but also a beneficial contribution to health due to its extensive medicinal properties. Despite the fact that $M$. oleifera has been extensively studied and used for medicinal purposes, further research is needed to further understand its therapeutic and other potential benefits, as well as to overcome many of the issues that remain with regard to scientific scrutiny of its medicinal uses. The $M$. oleifera wide range of pharmacological and phytochemical practises, as well as conventional medical applications, ought to be examined more and thoroughly such that a sound science examination of the literature's efficacy can be justified [15]. More research is required in this area, as well as clinical trials to assess the ad- verse effects or toxicity of $M$. oleifera in humans, in order to ensure that it can be used safely. The therapeutic capacity of this wonder tree needs to be explored more and scientifically analyzed so that more of its advantages can be realized and populations in need can benefit from it. Since this plant grows in a several of environments, it would be naive to assume a wide range of chemical ingredient concentrations and compositions in various sections of the tree. However, it is unknown how often the chemical makeup of organisms suited to different environments differs. As a result, in-depth research is needed to investigate this problem. Because of its many applications, the $M$. oleifera plant must be extensively cultivated in most areas where climatic conditions are favorable for its optimal growth. In this way, a maximum yield of the various usable pieces could be obtained, resulting in the maximum volume of goods of various kinds for mankind's benefit.

\section{Bibliography}

1. Asres K. "The major constituents of the acetone fraction of Ethiopian Moringa stenopetala leaves". Mansoura Journal of Pharmaceutical Sciences 11 (1995): 55-64.

2. Bais S., et al. "Anti-obesity and hypolipidemic activity of Moringa oleifera leaves against high fat diet-induced obesity in rats". Advances in Biology (2014): 1-9.

3. Bakre AG., et al. "Studies on neuropharmacological profile of ethanol extract of Moringa oleifera leaves in mice". Journal of Ethnopharmacology 149 (2013): 783-789.

4. Banji OJF., et al. "Immunomodulatory effects of alcoholic and hyrdoalcoholic extracts of Moringa oleifera Lam leaves". Indian Journal of Experimental Biology 50 (2012): 270-276.

5. Battacharya SB., et al. "Chemical investigations of the gum exudates from Sajna (Moringa oleifera)". Carbohydrate Research 102 (1982): 253-262.

6. Council of Scientific and Industrial Research (C.S.I.R). The Wealth of India, New Delhi (1962): 426-428.

7. Dayrit FM., et al. "Studies on Moringa oleifera seeds, part I: the antibiotic compound and its deactivation in aqueous solution". Philippine Journal of Science 119 (1990): 23-32.

8. Dieye AM., et al. "Medicinal plants and the treatment of diabetes in Senegal: survey with patients". Fundamental and Clinical Pharmacology 22 (2008): 211-216. 
9. Doughari JH., et al. "Antibacterial effects of Balanites aegyptiaca L. Drel. And Moringa oleifera Lam. on Salmonella Typhi". African Journal of. Biotechnology 6 (2007): 2212-2215.

10. Edoga CO., et al. "Blood sugar lowering effect of Moringa oleifera Lam in albino rats". International Journal of Scientific and Technology Research 3 (2013): 88-90.

11. Fahey JW. "Moringa oleifera: a review of the medical evidence for its nutritional, the rapeutic, and prophylactic properties". Part 1. Trees for Life Journal 1 (2005).

12. Muyibi SA and Evison LM. "Optimizing physical parameters affecting coagulation of turbid water with Moringa oleifera seeds". Water Research 29 (1995b): 2689-2695.

13. Nadkarni AK. "Indian Materia Medica". Popular Prakashan: Bombay (1976): 810-816.

14. Nagar PK., et al. "Cytokinins in developing fruits of Moringa pterigosperma Gaertn”. Physiology Plant 55 (1982): 45-50.

15. Ndabigengesere A and Narasiah KS. "Quality of water treated by coagulation using Moringa oleifera seeds". Water Research 32 (1998): 781-791.

\section{Assets from publication with us}

- Prompt Acknowledgement after receiving the article

- Thorough Double blinded peer review

- Rapid Publication

- Issue of Publication Certificate

- High visibility of your Published work

Website: www.actascientific.com/

Submit Article: www.actascientific.com/submission.php

Email us: editor@actascientific.com

Contact us: +91 9182824667 